\title{
Increasing Heat Stress Relief Produced by Coupled Coat Wetting and Forced Ventilation
}

\author{
A. Berman ${ }^{1}$ \\ Faculty of Agriculture, Hebrew University, Rehovot 76100, Israel
}

\section{ABSTRACT}

Coupling repeated wetting of the coat and forced ventilation is most efficient in removing heat stress in more humid climates. The procedure was initiated approximately $24 \mathrm{yr}$ ago and is widely used, but the impact of air velocity on the efficiency of heat stress relief has not been examined. This study examined the feasibility of using surface temperature for real-time estimation of heat stress relief. It was carried out in midsummer in Israel on 6 mature lactating Holsteins. A $15 \times 15 \mathrm{~cm}$ area on the right side of the body was thoroughly wetted. Hair surface and skin temperature on the wetted area and adjacent dry area were measured at 1-min intervals for 15 min while air movement was less than $0.1 \mathrm{~m} / \mathrm{s}$, and the sequence was repeated with air velocities of 0.5 to $3 \mathrm{~m} / \mathrm{s}$ perpendicular to the body surface. Because the cooled surface was small, the response to cooling was local. In 3 animals, the whole left side of the body also was wetted and exposed to forced ventilation $(1.5 \mathrm{~m} / \mathrm{s})$ to combine local cooling with larger body surface cooling. The air temperature was $29.5 \pm 0.05^{\circ} \mathrm{C}$, and the relative humidity was 56.7 $\pm 0.2 \%$. Rectal temperature and respiratory frequency indicated minor heat stress. Mean wet hair surface temperature (Thw) and wet skin temperature were 2.1 and $1.5^{\circ} \mathrm{C}$ lower than the respective dry hair surface temperature (Thd) and dry skin temperature. At an air velocity of $0.5 \mathrm{~m} / \mathrm{s}$, Thw was practically identical to that in still air and to Thd. At greater air velocities, Thw decreased immediately after wetting, and minimal values were reached within $1 \mathrm{~min}$, were maintained for 6 to $7 \mathrm{~min}$ after wetting, and reached $95 \%$ of the mean Thd value by 8 and 11 min after wetting at 1 and 2 $\mathrm{m} / \mathrm{s}$, respectively. Wetting the coat had the potential to reduce Thd temperature by 10 to $11^{\circ} \mathrm{C}$. The relatively small difference between Thd and Thw probably is due to heat flow from the body. The latter was estimated by comparing enthalpies at Thd, at Thw, and in the wet

\footnotetext{
Received March 13, 2008.

Accepted August 4, 2008.

${ }^{1}$ Corresponding author: berman@agri.huji.ac.il
}

bulb temperature predicted for Thd. Predicted heat loss rates were 736 and $1,012 \mathrm{~W} / \mathrm{m}^{2}$ at air velocities of 1 and $2 \mathrm{~m} / \mathrm{s}$, respectively, compared with $164 \mathrm{~W} / \mathrm{m}^{2}$ predicted for the dry surface from the thermal balance model. Increasing heat loss from the left side reduced wet surface temperatures on right side, indicating that larger body surface cooling reduced heat flow to the skin on the right body surface. Heat extraction from the wet body surface is thus reduced by large body surface cooling and depends on the thermal state. The efficiency of heat stress relief may be detected by surface temperature monitoring and may be improved by adjusting the interval between wettings to the changes in surface temperature.

Key words: heat stress relief, coat wetting, surface temperature

\section{INTRODUCTION}

Thermal stress is a major element limiting dairy cattle productivity in warmer climates as well as in the warmer season in temperate climates. Provision of adequate shade reduces the radiant component of heat load. Forced ventilation increases convective heat loss, but is mostly effective in the lower range of stressing air temperatures. Evaporative cooling is the main means for heat stress relief at higher temperatures. It is implemented in a variety of modes that differ conceptually and technically.

At one extreme is environmental cooling by forced-air circulation through a wet pad or by fogging. When fogging or misting is used, droplets sprayed in the air vary in mean size and size distribution according to the pressure and nozzle type. Droplet evaporation depends on droplet size as well as on ambient conditions. For misting systems that produce droplets of approximately 65 $\mu \mathrm{m}$, the fraction evaporated ranges from 32 to $66 \%$ at $27^{\circ} \mathrm{C}$ and $73 \%$ relative humidity $(\mathbf{R H})$ and at $31^{\circ} \mathrm{C}$ and $54 \% \mathrm{RH}$, respectively. The effects of temperature and $\mathrm{RH}$ on evaporation are opposite and are numerically similar (Singletary et al., 1996). In general, evaporative cooling of a space requires a restriction of air interchange between the space and the outdoor environment (Esmay, 1969). 
At the other extreme is direct cooling of the animal by wetting the coat, with subsequent evaporation of the water contained in it. The coat may retain only a small amount of water so that repeated wetting is required. Reducing the water droplet size and increasing the duration of spraying would increase the humidity in the atmosphere of the animal and would restrict evaporation from the coat. Coupling wetting with forced ventilation enhances replacement of the air surrounding the animal. Frequent air replacement (i.e., greater air velocity) prevents moisture from accumulating in the air surrounding the animal and maintains a humidity gradient between the coat and the surrounding air. Evaporation from the coat may thus become practically independent of ambient humidity. This feature makes coupling wetting with forced ventilation particularly advantageous for moderately warm but more humid climates.

The latter approach was initially implemented in 1984 (Flamenbaum et al., 1984, 1986) and its application was reported in several studies, but the interaction between evaporation of water from the hair coat and air velocity has not been critically examined. The efficiency of heat stress alleviation is conventionally measured by animal performance or animal responses (e.g., body temperature or respiratory frequency), which require extended periods of time. The evaluation of heat stress relief in real time would reduce the time required for management responses to changes in heat stress. The patterns of peripheral temperature during the cooling cycle and the impact of air velocity on these patterns might serve as estimates of the desired frequency of surface wettings. The present study examined the impact of air velocity on the pattern of surface and skin temperatures after wetting the coats of lactating cows, in conjunction with estimation by a thermal balance model.

\section{MATERIALS AND METHODS}

\section{Animals and Experimental Design}

The study was carried out in Israel on 6 lactating Holstein cows in their second to fourth lactation from July to September 2007. On separate occasions, each cow was tied in stanchions in a closed room. An area of approximately $15 \times 15 \mathrm{~cm}$ on the right surface of the body, anterior to the hip bone protrusion, was wetted by using a hand sprayer until excess water flowed from it. Hair surface temperature on the dry and adjacent wetted areas (Thd, Thw) and skin temperature on the dry and adjacent wetted areas (Tsd, Tsw) were measured at 1-min intervals for 15 to $20 \mathrm{~min}$ while air movement around the cows was close to nil (i.e., less than $0.1 \mathrm{~m} / \mathrm{s}$ ). The sequence was repeated with air velocity increased from still air to $0.5,1.0,1.5,2.0$, and
$3 \mathrm{~m} / \mathrm{s}$ by a variable-velocity fan directed to produce airflow perpendicular to the body surface. The protocol was repeated 6 times on different cows on different days. In the latter 3 animals, the same protocol was followed, with the inclusion of wetting of the whole left body surface coupled with forced ventilation $(1.5 \mathrm{~m} / \mathrm{s})$ as an additional experimental variant.

\section{Measurements}

Multidirectional air velocity was measured to \pm 0.05 $\mathrm{m} / \mathrm{s}$ with a circular thermocouple system (Hastings Air Meter model B-27, Hastings Raydist Inc., Hampton VA). Rectal and skin temperatures were measured to $\pm 0.1^{\circ} \mathrm{C}$ with a thermistor probe (probe models 406 and 427 for rectal and skin temperatures, respectively, time constant $0.3 \mathrm{~s}$, and monitor model 4000, Yellow Springs Instruments Inc., Yellow Springs, $\mathrm{OH}$ ). The hair surface temperature was measured to $\pm 0.2^{\circ} \mathrm{C}$ with an infrared radiometer (model Raynger ST 20 Pro, Raytek Corp., Santa Cruz, CA) held at $20 \mathrm{~cm}$ above the wet and dry skin areas and perpendicular to their surface. Skin temperature was estimated by applying the sensor to the skin under the hair coat. This was a compromise, because shaving would have altered temperature gradients, and inserting a sensor into the hair coat would have disturbed the integrity of the insulation layer. Air temperature and humidity were measured in the vicinity of the animals to $\pm 0.1^{\circ} \mathrm{C}$ and $\pm 2.0 \% \mathrm{RH}$, respectively, by using a dual-probe system (Testo 451, Testoterm Inc., Randolph NJ). The hair coat was approximately 1.5 to $2 \mathrm{~mm}$ thick, as measured with a caliper in the sampling area.

\section{Heat Flow Estimation}

The flow of heat from the skin to wet coat was estimated in 2 different ways: a) by comparing the change in enthalpy associated with adiabatic cooling from Thd to Thw with that of cooling from Thd to the respective wet bulb temperature (Twb); and b) by a thermal balance model for cattle (McGovern and Bruce, 2000) modified to represent a summer-adapted lactating Holstein cow (Berman, 2005).

Enthalpies of the air and the water vapor contained in it at Thd, Thw, and the expected Twb of Thd were calculated by gas law equations (Monteith, 1973; Campbell and Norman, 1998). The hair coat was estimated to consist of $90 \%$ air (Arkin et al., 1991), so that enthalpy changes of the hair fibers would only slightly affect enthalpy changes in the coat layer.

The enthalpy of air (ha, kJ/kg of dry air) was calculated as 


$$
\text { ha }=\text { Ta } \times \rho \mathrm{a} \times \text { sha, }
$$

where Ta is air temperature $\left({ }^{\circ} \mathrm{C}\right), \rho \mathrm{a}$ is air density $(\mathrm{kg} /$ $\left.\mathrm{m}^{3}\right)$, and sha is the specific heat of air $(1.01 \mathrm{~kJ} / \mathrm{kg}$ of dry air),

$$
\rho \mathrm{a}=(\mathrm{P} \times \mathrm{M}) /(\mathrm{R} \times \mathrm{K})=(101.3 \times 29) /(8.31 \times \mathrm{K}),
$$

where $\mathrm{P}$ is air pressure $(\mathrm{kPa}), \mathrm{M}$ is molecular weight (for air, $28.97 \mathrm{~g}$ ), $\mathrm{R}$ is the gas constant $(8.31 \mathrm{~J} / \mathrm{mol} \cdot \mathrm{K}$ ), and $\mathrm{K}$ is the absolute temperature (kelvin).

The enthalpy of water vapor (hw, $\mathrm{kJ} / \mathrm{kg}$ of dry air) for ambient and cooled air RH (RHa and RHc, respectively) was calculated as

$$
\mathrm{hw}=(\mathrm{Ta} \times \mathrm{shw}) \times(\rho \mathrm{w} / \rho \mathrm{a}),
$$

where Ta is air temperature $\left({ }^{\circ} \mathrm{C}\right)$, shw is the specific heat of water vapor $(1.88 \mathrm{~kJ} / \mathrm{kg})$, and $\rho \mathrm{w}$ is the water vapor density $\left(\mathrm{kg} / \mathrm{m}^{3}\right)$, calculated by

$$
\rho \mathrm{w}=\left(\mathrm{Pw} \times 10^{-3}\right)[\mathrm{M} /(\mathrm{R} \times \mathrm{K})]=(21.7 \times \mathrm{Pw}) / \mathrm{K},
$$

where $\mathrm{Pw}$ is water vapor pressure $(\mathrm{kPa}), \exp [52.575-$ $(6790.5 / \mathrm{K})-(5.0281 \times \ln \mathrm{K})]$; and $\mathrm{M}$ is the molecular weight of water vapor $(18 \mathrm{~g} / \mathrm{mol})$.

The ha, hw, and their sum were used to estimate the enthalpy of air entrapped in the hair coat. The latent heat of evaporation of water contained in the wet hair coat was estimated as 2,430 kJ/kg (Monteith, 1973). In the enthalpy analyses, the dry coat was presumed to be in equilibrium with the vapor pressure in the surrounding air. In addition, the soaked coat was presumed to be saturated with water and to dry out gradually thereafter. The difference between the expected Twb of the wet coat when wetted and its actual temperature was presumed to represent heat coming from the body. The latter was estimated by the difference between the enthalpy of air at the expected Twb and that at the wet coat temperature.

A cattle thermal balance simulation model (McGovern and Bruce, 2000), modified to represent a summeradapted lactating Holstein cow (Berman, 2005), was used to simulate responses of a cow yielding $35 \mathrm{~kg}$ of milk/d, with a $220 \mathrm{~g} / \mathrm{m}^{-2}$ per h skin water loss, a hair coat depth of $2 \mathrm{~mm}$, a body temperature of $39.0^{\circ} \mathrm{C}$, and exposed to an air temperature of $29^{\circ} \mathrm{C}$, a $\mathrm{RH}$ of $57 \%$, and an air velocity of $1.5 \mathrm{~m} / \mathrm{s}$. Except but the skin water loss rate, these represent experimental conditions as measured in this study. The skin water loss rate was measured in an earlier study (Berman, 1971). The model produced estimates of heat flow from the core to the skin, heat flow through the coat, and heat flow through the boundary layer between the coat and air, as well as temperatures of the body core, skin, and coat surface. The thermal balance model was further validated by comparing the predicted skin and surface temperatures with those measured on the cows.

\section{Data Analysis}

The effects of air velocity on mean skin and hair temperatures were estimated by the Type III variance in the General Linear Model (SAS Institute, Cary, NC) and its CONTRAST statement. The model used was composed of surface temperature as the dependent variable and air velocity, time after wetting, and the air velocity $\times$ time after wetting interaction as independent variables. In the latter experimental group, left side wetting (coupled with forced ventilation) was an additional independent variable.

\section{RESULTS}

Average ambient conditions during measurements taken at 10-min intervals were (means \pm SEM) 29.5 $\pm 0.1^{\circ} \mathrm{C}$ and $56.7 \pm 0.2 \% \mathrm{RH}$ for air temperature and $\mathrm{RH}$, respectively. Rectal temperature and respiratory frequency were $38.8 \pm 0.1$ and $54.5 \pm 0.6$, respectively, indicating minor heat stress. The average Tsd, Tsw, Thd, and Thw ( $\mathrm{n}=456$ for all variables) were $35.2 \pm$ $0.1,33.1 \pm 0.1,34.7 \pm 0.1$, and $33.2 \pm 0.1^{\circ} \mathrm{C}$, respectively. Mean wet surface temperatures, averaged over all air velocities, were 2.1 and $1.5^{\circ} \mathrm{C}$ lower than the respective dry surface temperatures. Only minor changes occurred in Tsd and Thd in the 18 min after wetting (Figure 1), whereas mean Thw, after an initial decrease immediately after wetting, gradually increased to reach Thd by 15 to 16 min after wetting.

Heat loss from the skin was markedly dependent on the velocity of air flow over it, as demonstrated by the changes in Thw at different air velocities (Figure 2 ). At an air velocity of $0.5 \mathrm{~m} / \mathrm{s}$, the Thw was practically identical to that measured in still air. It was temporarily reduced by the initial application of water, gradually increased thereafter, and reached maximal, typical values by 4 min after wetting. At the greater air velocities, Thw decreased immediately after wetting, and minimal values were reached within 1 min after wetting and were maintained for $10 \mathrm{~min}$ after wetting. These changes were accelerated at an air velocity of $2 \mathrm{~m} / \mathrm{s}$ : temperatures were maintained for 6 to $7 \mathrm{~min}$ after wetting and reached those in still air by $13 \mathrm{~min}$ after wetting. The Thw reached $95 \%$ of the mean Thd value by 8 and $11 \mathrm{~min}$ after wetting at air velocities of 1 and $2 \mathrm{~m} / \mathrm{s}$, respectively. This may estimate the 


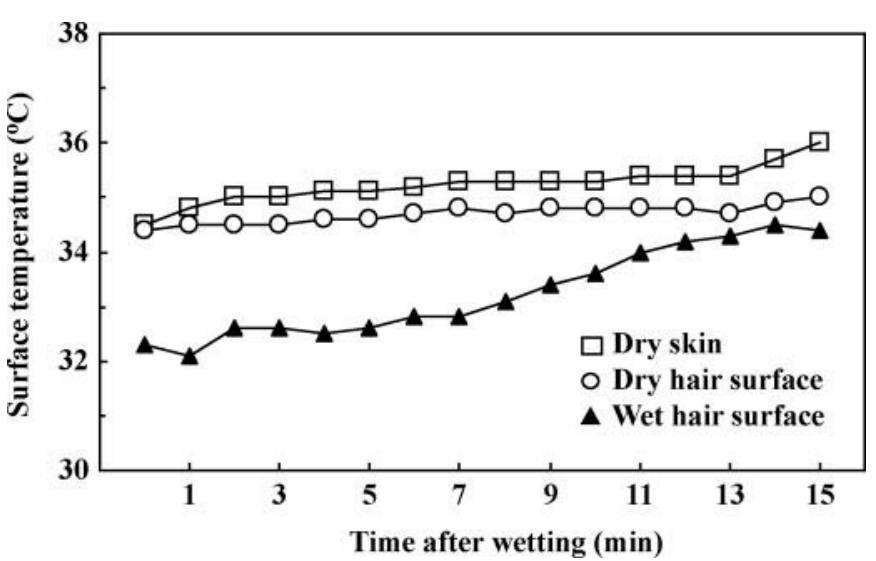

Figure 1. Mean dry skin, dry surface, and wet surface radiant temperatures $\left({ }^{\circ} \mathrm{C}\right)$ measured at 1 -min intervals for 15 min after wetting in 6 cows. The pooled standard errors of the means are $0.04,0.02$, and $0.05^{\circ} \mathrm{C}$, respectively. Each data point is the mean of measurements taken in still air and at air velocities of 1 and $2 \mathrm{~m} / \mathrm{s}$, at an air temperature of $29.5 \pm 0.1^{\circ} \mathrm{C}$ and at $56.7 \pm 0.2 \%$ relative humidity.

time required for a 2 -mm-thick wet coat to reach nearly complete evaporation of the water contained in it at these air velocities.

Temperatures of the dry hair surface were practically constant during the observation period. Air flow reduced the surface temperature, but the decrease was similar at the air velocities of 1 and $2 \mathrm{~m} / \mathrm{s}$. The same pattern was observed for dry skin temperature, albeit at a slightly higher temperature. In neither case was a pattern of change observed during the observation period.

The effect of air velocity on mean skin and surface temperatures was evaluated for the 2- to 7 -min period after wetting the coat, during which they were stable (Table 1). When air was still, the dry skin and dry hair surface temperatures were similar. Temperatures were reduced by increasing the air velocity, particularly for the wet hair surface: the change from still air to an air velocity of $1 \mathrm{~m} / \mathrm{s}$ reduced the temperature of dry skin by $0.5^{\circ} \mathrm{C}$, that of the dry hair surface by $0.8^{\circ} \mathrm{C}$, and that of the wet surface by $2.6^{\circ} \mathrm{C}$. A further increase in air velocity from 1 to $2 \mathrm{~m} / \mathrm{s}$ did not further reduce skin and

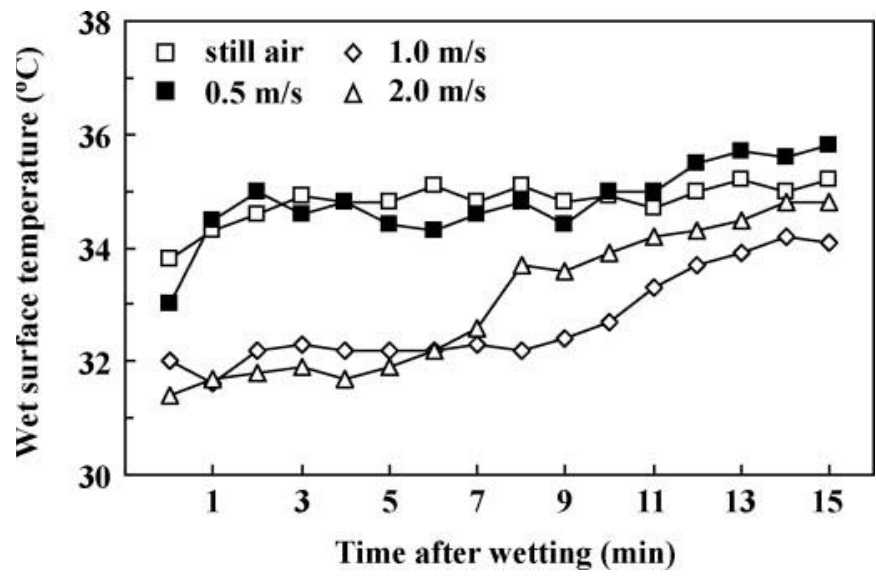

Figure 2. Changes in hair surface radiant temperature $\left({ }^{\circ} \mathrm{C}\right)$ after wetting when exposed to still air or air velocities of $0.5,1.0$, and 2 $\mathrm{m} / \mathrm{s}$. The pooled standard errors of the means are $0.08,0.11,0.06$, and $0.05^{\circ} \mathrm{C}$, respectively. Each data point is an average of measurements taken on 6 cows at an air temperature of $29.5 \pm 0.1^{\circ} \mathrm{C}$ and at $56.7 \pm$ $0.2 \%$ relative humidity.

surface temperatures, except for a trend for air velocity to reduce the wet surface temperature $(P<0.11)$.

It is important that the difference between dry and wet hair surface temperatures was not large. Wet surface temperatures might have been lower and closer to the Twb, which represent the adiabatic cooling potential of air by the evaporation of water in it. The Twb that might have been reached by the dry hair surface was estimated from the psychrometric chart. For this purpose, we presumed that humidity in the hair coat layer represented by Thd was close to or equal to humidity in the air and that the hair coat layer represented by Thw was saturated with water. The difference between Thd and Twb indicates that the evaporation of water had the potential to reduce peripheral temperatures in these conditions by 10 to $11^{\circ} \mathrm{C}$ (Table 2 ). This contrasts with the 0.8 to $2.2^{\circ} \mathrm{C}$ difference between Thd and Thw. The difference between Thd and Thw varied with air velocity, which was not a great innovation.

The relatively small difference between Thd and Thw was likely not due to heat gain from the air, because the air temperature was lower than the surface

Table 1. Dry skin (Tsd) and dry (Thd) and wet (Thw) hair surface temperatures (means \pm SEM, ${ }^{\circ} \mathrm{C}$ ) at 3 air velocities (still air, 1 and $2 \mathrm{~m} / \mathrm{s}$ ) during the 2 - to 7 -min period after wetting the coat

\begin{tabular}{lcccccccc}
\hline & \multicolumn{2}{c}{ Tsd } & & \multicolumn{2}{c}{ Thd } & & \multicolumn{2}{c}{ Thw } \\
\cline { 2 - 3 } \cline { 8 - 9 } Air velocity & Mean $^{1}$ & SEM & & Mean & SEM & & Mean & SEM \\
\hline Still air & $36.3^{\mathrm{a}}$ & 0.1 & & $35.6^{\mathrm{a}}$ & 0.6 & & $34.8^{\mathrm{a}}$ & 1.3 \\
$1 \mathrm{~m} / \mathrm{s}$ & $36.4^{\mathrm{b}}$ & 0.1 & & $34.9^{\mathrm{b}}$ & 0.6 & & $32.7^{\mathrm{b}}$ & 1.3 \\
$2 \mathrm{~m} / \mathrm{s}$ & $36.4^{\mathrm{b}}$ & 0.1 & & $34.6^{\mathrm{b}}$ & 0.5 & & $32.6^{\mathrm{b}}$ & 1.1 \\
\hline
\end{tabular}

${ }^{a, b}$ Means within a column marked by different superscripts are significantly different $(P<0.01)$. 
Table 2. Temperature $\left({ }^{\circ} \mathrm{C}\right)$ of the dry (Thd) and wet (Thw) hair surface, estimated relative humidity $(\mathrm{RH})$ in the hair surface ( $\mathrm{RH} \%)$, wet bulb temperature (Twb) estimated for Thw, and respective differences at 3 air velocities (still air, 1 and $2 \mathrm{~m} / \mathrm{s}$ ) over the sampling area ${ }^{1}$

\begin{tabular}{lcccccc}
\hline Air velocity & Thd & RH\% & Thw & Twb & Thd - Twb & Thd - Thw \\
\hline Still air & 35.6 & 41 & 34.8 & 24.6 & 10.2 & 0.8 \\
1 & 34.9 & 42 & 32.7 & 24.0 & 10.9 & 2.2 \\
2 & 34.6 & 42 & 32.6 & 24.0 & 10.6 & 2.0 \\
\hline
\end{tabular}

${ }^{1}$ Respective SEM presented in Table 1.

temperature. It was probably due to heat flow from the body. Heat flow from the body was estimated by comparing the enthalpies at Tsd, Thd, Thw, and predicted Twb (Table 3). To calculate the enthalpy of the hair coat, we used the hair diameter and hair density data of Holstein cows in warm climates (Berman and Volcani, 1961; Gutierrez et al., 1984; Pinheiro and Da Silva, 1998; Bertipaglia et al., 2005), and we presumed that the hair coat layer consisted of 90 to $95 \%$ air. We estimated the enthalpies of Tsd and Thd by assuming that the moisture content of the skin was in equilibrium with the humidity of the air, and for Thw we assumed that the hair surface was saturated with moisture. The enthalpy of Tsd (not presented) was very close to that of Thd. The enthalpies of both Tsd and Thd were only slightly affected by air velocity. The enthalpy of Thw was consistently greater than that of Twb and was decreased in the presence of air velocities of 1 to $2 \mathrm{~m} / \mathrm{s}$, presumably owing to the enhanced convective heat loss. The difference between the enthalpies of Thw and Twb estimated the heat needed to increase the temperature of wet hair from the expected Twb to that measured as Thw.

The effect of this difference in enthalpy heat content of the hair coat on thermal balance was estimated as follows. Assuming that the hair coat consisted of $90 \%$ air and that the mass of $1 \mathrm{~m}^{3}$ of air at $30^{\circ} \mathrm{C}$ was 1.167 $\mathrm{kg}$, the mass of air contained in a 2-mm-thick hair coat was approximately $0.0022 \mathrm{~kg} / \mathrm{m}^{2}$ of body surface. At this temperature, the enthalpy of dry air was approximately $40 \mathrm{~kJ} / \mathrm{kg}$ of dry air so that heat contained in the dry hair coat layer was unlikely to play a significant role, if any, in the thermal balance of the animal. This conclusion would not be markedly affected by coat thickness.

In the next step, the consequences of the evaporation of water contained in the coat were examined. When the coat was soaked with water, a 2-mm-thick hair coat might be seen as consisting of a 2-mm-thick water layer, equivalent to $0.2 \mathrm{l} / \mathrm{m}^{2}$. The enthalpy of such a water layer was approximately $486 \mathrm{~kJ} / \mathrm{m}^{2}$. The Thw was highly dependent on air velocity (Figure 2). In still air and at an air velocity of $0.5 \mathrm{~m} / \mathrm{s}$, the Thw was practically stable for more than $15 \mathrm{~min}$. The period to the onset of an increase in Thw represented the duration of full coat wetness. The Thw remained within $95 \%$ of the mean values in still air for 11 and 8 min after wetting at air velocities of 1 and $2 \mathrm{~m} / \mathrm{s}$, respectively. The values of Thw in still air were very close to those of Thd at air velocities of 1 and $2 \mathrm{~m} / \mathrm{s}$. The latent heat content of a 2-mm-thick water layer was converted into heat loss per minute for the duration of the full wetness period and was translated into an hourly rate of heat loss. The predicted rates of heat loss were 736 and $1,012 \mathrm{~W} / \mathrm{m}^{2}$ at air velocities of 1 and $2 \mathrm{~m} / \mathrm{s}$, respectively. These data were compared with the skin heat loss predicted from the thermal balance model for cattle.

The thermal balance model, like any other model, needs validation. The model used here was validated previously (McGovern and Bruce, 2000; Berman, 2005), but it was further examined to determine whether its predictions applied to this particular set of data. For this purpose, we computed the thermal balance of a cow similar to those in the experiment (i.e., producing approximately $35 \mathrm{~kg}$ of milk/d, having a 2-mm-thick hair coat, and exposed to an air temperature of $29^{\circ} \mathrm{C}$ and an air velocity of $1.5 \mathrm{~m} / \mathrm{s}$. The core, skin, and hair surface temperatures predicted by the thermal balance model were compared with those measured in the experiment (Table 4). The temperatures predicted were sufficiently close to those measured to justify the use of predicted flow of evaporative and nonevaporative heat through the hair coat as a further step in the analysis. The total predicted flow of heat to a nonwetted skin was $164 \mathrm{~W} / \mathrm{m}^{2}$. The calculated heat loss from a wet coat exposed to air velocities of 1 and $2 \mathrm{~m} / \mathrm{s}$ (i.e., 736 and $1,012 \mathrm{~W} / \mathrm{m}^{2}$, respectively) was 4 - to 6 -fold greater

Table 3. Total enthalpies (kJ/kg of dry air) of the dry hair surface (Thd), of the wet hair surface (Thw), of the dry skin (Tsd), and at the wet bulb temperature (Twb) calculated from mean Thd values for the 2 to $7 \mathrm{~min}$ after wetting the coat

\begin{tabular}{llllc}
\hline Air velocity & Thd & Thw & Twb & Thw - Twb \\
\hline Still air & 80.8 & 131.4 & 105.9 & 25.5 \\
1 & 79.5 & 123.8 & 105.0 & 18.8 \\
2 & 79.9 & 124.6 & 106.9 & 17.7 \\
\hline
\end{tabular}




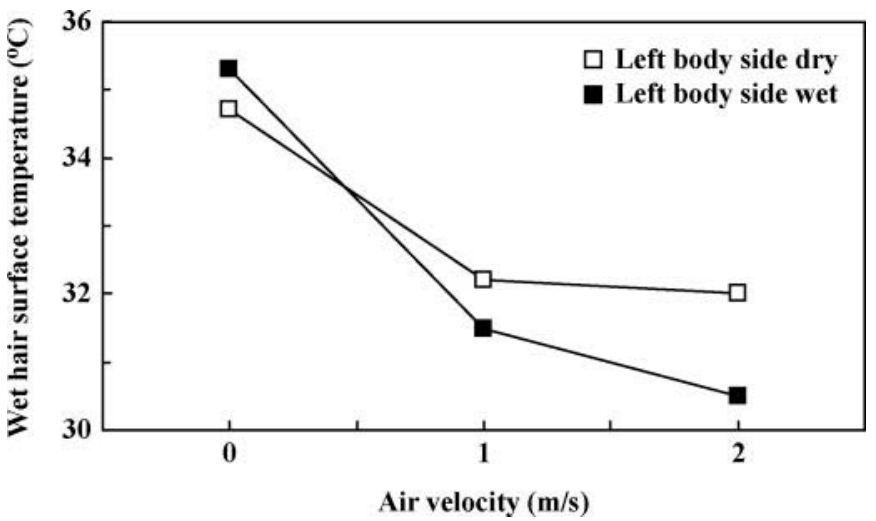

Figure 3. Hair surface radiant temperature $\left({ }^{\circ} \mathrm{C}\right)$ of the wet area on the right side of the body exposed to still air or air velocities of 1 and $2 \mathrm{~m} / \mathrm{s}$ when the left side of the body was either dry or wetted and exposed to an air velocity of $1.5 \mathrm{~m} / \mathrm{s}$. This procedure examined whether changes in temperature on the test area are affected by increased heat loss from other body parts. The pooled standard errors of the means are $0.2,0.15$, and $0.18^{\circ} \mathrm{C}$, respectively. Each data point is an average of measurements taken on 3 cows at an air temperature of $29.5 \pm 0.1^{\circ} \mathrm{C}$ and $56.7 \pm 0.1 \%$ relative humidity.

than that from a dry coat. This suggests a very large cooling potential for hair wetting.

This large heat loss from the wet coat was maintained over short periods without a further decline in the surface temperature owing to a large outflow of heat into the small wetted area. To examine whether this would be so when heat loss from the body was larger, we added wetting of the contralateral side of the body concurrently with exposing it to an air velocity of 1.5 $\mathrm{m} / \mathrm{s}$ to the experimental protocol. Increasing heat loss from the left side of the body enhanced the reduction in temperature with increasing air velocity, as indicated by the interaction $(P<0.01)$ between air velocity and the left side cooling effect. This effect was largest for Thw (Figure 3), followed by Thd and Tsd.

\section{DISCUSSION}

Wetting the coat coupled with forced ventilation as a heat stress-relief procedure was initially introduced into the management of dairy cattle in warm environments more than 24 yr ago (Flamenbaum et al., 1984, 1986). In that study, the effects of duration of wetting, number of cooling periods, and density of cows in the holding area on rectal temperature were examined. This approach was also later extended by setting it up along a manger. The use of combined sprinkling and forced ventilation to relieve the heat stress of dairy cows has been examined in several countries (Huang et al., 1986; Turner et al., 1992; Mena Guerrero et al., 1993; Wang et al., 1993; Omar et al., 1996; Lee et al., 1999; Bucklin and Bray, 2005). However, elements of the procedure that modify its efficiency for heat stress relief (e.g., frequency of wetting, air velocity, and duration of forced ventilation) had not been critically examined, nor had the portion of the body surface that was wetted or exposed to flowing air.

Wetting of the hair coat can be done by methods that vary in the impact on ambient humidity, and hence evaporation from the wet coat. These methods also vary in the depth of moisture penetration into the hair layer, and hence in the distribution of the latent heat between that coming from the body and that originating from the ambient air. The size and velocity of water droplets sprayed affect the ratio of water that evaporates into the air. During misting, 50 to $60 \%$ of water evaporates at ambient $65 \% \mathrm{RH}$ (Bottcher et al., 1993). Even when water is atomized to $55-\mu \mathrm{m}$-diameter droplets, water particles collect on the hair surface (Armstrong et al., 1993). When water is sprayed as droplets of $0.5 \mathrm{~mm}$ diameter or larger, they penetrate the coat.

The evaporation of water from the wet coat depends on the air velocity over it. The nominal air velocity measured at a distance from the animal surface may differ considerably from that on the surface of the animal. Air flow of $1 \mathrm{~m} / \mathrm{s}$ at $1 \mathrm{~m}$ over the back of the animals, perpendicular to the longitudinal axis of the cow, may produce air velocities over the animal surface that vary from approximately 0.3 to more than $0.6 \mathrm{~m} / \mathrm{s}$ (Berman, 2006). The time required for water contained in the coat to evaporate was not examined, nor was the effect of air velocity. This period of time would determine the optimal intervals between wettings, the extent to which heat stress was relieved, and the extent of the water discharge into the system of the animal.

The time required for evaporation of water contained in the coat also depends on the amount of water retained in it. The latter is determined mostly by the thickness of the coat. In this study, the coat thickness was approximately 1.5 to $2 \mathrm{~mm}$, typical for summer-adapted Holstein cattle in a good management system (Berman, 2004). At 29 to $30^{\circ} \mathrm{C}$ and $57 \% \mathrm{RH}$, conditions typical of many warm climates, the time required for water con-

Table 4. Comparison of thermal balance model means of rectal and surface temperatures with the respective means in this experiment

\begin{tabular}{lcc}
\hline Item & Model $^{1}$ & Experiment $^{2}$ \\
\hline Skin temperature, ${ }^{\circ} \mathrm{C}$ & 36.4 & 36.4 \\
Dry hair coat temperature, ${ }^{\circ} \mathrm{C}$ & 34.2 & 34.6 \\
Core temperature,${ }^{\circ} \mathrm{C}$ & 39.0 & 38.9 \\
Coat heat flow, $\mathrm{W} / \mathrm{m}^{2}$ & 96 & \\
\hline
\end{tabular}

${ }^{1}$ Predicted for cows producing $35 \mathrm{~kg}$ of milk/d, with 2 -mm hair coat thickness, at $29^{\circ} \mathrm{C}, 57 \%$ relative humidity, and at an air velocity of $1.5 \mathrm{~m} / \mathrm{s}$.

${ }^{2}$ Means for dry hair surface temperature at air velocities of 1 and $2 \mathrm{~m} / \mathrm{s}$ for 2 to $7 \mathrm{~min}$ after wetting. 
tained in the coat to evaporate almost completely was of the order of 8 to $11 \mathrm{~min}$. This was much longer than the interval between wettings in the aforementioned reports, which suggests a significant potential for reducing water use in cooling systems based on wetting the skin. The effect of wetting on Thw and the duration of wetting were highly dependent on air velocity, which in itself is not a great innovation. In still air, wetting did not reduce surface temperatures.

In this study with air velocities at 1 and $2 \mathrm{~m} / \mathrm{s}$, evaporation of water from the hair coat was associated with a 1 to $2.2^{\circ} \mathrm{C}$ reduction in temperature. Similar reductions in skin temperature and a dependence on air velocity were recorded in other reports (Thiagarajan et al., 1978; Omar et al., 1996; Arcaro Júnior et al., 2005). Under ideal conditions, adiabatic cooling might cause markedly greater reductions in skin temperature, close to Twb, similar to those reached by vegetation under windy conditions (Liu and Kang, 2006) and as estimated for the skin and hair surface. This is relevant in 2 respects.

Convective heat loss from the skin is proportional to the difference between body surface and air temperatures. Maintaining a higher surface temperature benefits the animal because it enhances convective heat loss. Latent heat loss from the skin, in contrast, is practically independent of ambient temperature (Gebremedhin and $\mathrm{Wu}, 2002$ ). The origin of the heat that sustains skin temperature above the estimated Twb is of interest. In shaded animals, as in this study, incident radiant heat is a rather unlikely source of such heat. Vasomotor-controlled heat flow from the body core to the skin is another alternative (Bligh, 1998). The experimental design adopted in this study made it possible to detect such variable heat flow to the body periphery by modifying it. The animals were under only minor thermal stress, as evidenced by their rectal temperature $(38.8 \pm 0.1)$ and respiratory frequency $(54.5 \pm 0.6)$ during the measurements, which made them sensitive to relatively small changes in heat loss. The wetting of a small part of the body surface only, as well as concurrent wetting of a large part of body surface made it possible to examine the effects of cooling of a small skin area as well as the effects of larger body surface cooling. In both cases, the impact of wetting on the surface temperature was enhanced by the velocity of airflow. When in still air, the wet surface temperature was close to the dry surface temperature (i.e., the heat flow to the surface was equal to or greater than the heat loss by water evaporation). The reduction in surface temperature at air velocities of 1 and $2 \mathrm{~m} / \mathrm{s}$ indicates that the flow of heat to the surface was smaller than that extracted by water evaporation. The reduction in Thw on the small skin area on the right side of the body was greater when the left side of the body was cooled. This strongly suggests that cooling of the left side reduced the flow of heat to the body periphery on the right side of the body. It indicates that heat extraction from the body core by water evaporation from the skin surface is likely to be reduced when heat loss is great or heat stress is diminished, thereby reducing the benefits of peripheral cooling. A smaller heat extraction diminishes the impact of surface cooling on the heat balance of the animal.

Such transitions in thermal state may be detected by the presence of lower wet surface temperatures of extended duration. It is obvious that these changes in thermal state are highly dependent on ambient conditions (temperature, air velocity, humidity, radiant heat, animal density) as well as on heat loss characteristics of animal metabolic heat production. Their occurrence would therefore be rather difficult to predict in the different conditions that occur in dairy farming systems. Monitoring the surface temperature by infrared thermometry, to detect the presence of larger reductions in surface temperature, may detect such changes in thermal state. It would make the improvement of heat stress relief possible by adjusting the frequency and duration of wetting as well as by adjusting the air velocity to the thermal state of the animals. Such adjustments would also make it possible to reduce the input of water into the system of the animal.

\section{REFERENCES}

Arcaro Júnior, I., J. R. P. Arcaro, C. R. Pozzi, C. Del Fava, H. Fagundes, S. V. Matarazzo, and J. E. de Oliveira. 2005. Physiological responses of dairy cows to fan plus sprinkler in holding pen. Cienc. Rural 35:639-643.

Arkin, H., E. Kimmel, A. Berman, and D. Broday. 1991. Heat transfer properties of dry and wet furs of dairy cows. Trans. ASAE 34:2550-2558.

Armstrong, D. V., W. T. Welchert, and F. Wiersma. 1993. Environmental modification for dairy cattle housing in arid climates. Pages 1223 1231 in Livestock Environment IV Conference. E. Collins, ed. Am. Soc. Agric. Eng., St. Joseph, MI.

Berman, A. 1971. Thermoregulation in intensively lactating cows in near natural conditions. J. Physiol. 215:477-489.

Berman, A. 2004. Tissue and external insulation estimates and their effects on prediction of energy requirements and of heat stress. J. Dairy Sci. 87:1400-1412.

Berman, A. 2005. Estimates of heat stress relief needs for Holstein dairy cows. J. Anim. Sci. 83:1377-1384.

Berman, A. 2006. Extending the potential of evaporative cooling for heat-stress relief. J. Dairy Sci. 89:3817-3825.

Berman, A., and R. Volcani. 1961. Seasonal and regional variations in coat characters of dairy cattle. Aust. J. Agric. Res. 12:528-538.

Bertipaglia, E. C. A., R. G. Silva, and A. S. C. Maia. 2005. Fertility and hair coat characteristics of Holstein cows in a tropical environment. Anim. Reprod. Belo Horiz. 2:187-194.

Bligh, J. 1998. Mammalian homeothermy: An integrative thesis. J. Thermal Biol. 23:143-258.

Bottcher, R. W., I. B. Singletary, and G. R. Baughman. 1993. Humidity effects on evaporative efficiency of misting nozzles. Pages 375-383 in Livestock Environment IV Conference E. Collins, ed. Am. Soc. Agric. Eng., St. Joseph MI. 
Bucklin, R. A., and D. R. Bray. 2005. Dairy cooling systems in Florida. Paper no. 054113, Am. Soc. Agric. Eng. Int. Mtg., Tampa, FL. Am. Soc. Agric. Eng., St. Joseph, MI.

Campbell, G. S., and J. M. Norman. 1998. An Introduction to Environmental Biophysics. 2nd ed. Springer-Verlag, New York, NY.

Esmay, M. L. 1969. Principles of Animal Environment. The Avi Publishing Co., Westport, CO.

Flamenbaum, I., A. Berman, and D. Wolfenson. 1984. Summer effect on milk production and conception rate of high yielding dairy cows in Israel and its alleviation. Page 2 in 35th Ann. Mtg. Eur. Assoc. Anim. Prod., The Hague, the Netherlands.

Flamenbaum, I., D. Wolfenson, M. Mamen, and A. Berman. 1986 Cooling dairy cattle by a combination of sprinkling and forced ventilation and its implementation in the shelter system. J. Dairy Sci. 69:3140-3147.

Gebremedhin, K. G., and B. Wu. 2002. Simulation of sensible and latent heat losses from wet-skin surface and fur layer. J. Therm. Biol. 27:291-297.

Gutierrez, M. M. Milanes, M. Morais, and Z. Davidova. 1984 Relationship between coat characteristics and milk production of Holstein-Friesian cows in the rainy season. Rev. Salud Anim. 6:605-611.

Huang, C. S., R. Z. Li, and G. X. Cao. 1986. Effects of increasing air speed and of sprinkling on the performance of dairy cows in the hot season. J. Nanjing Agric. Univ. 2:102-109.

Lee, S., C. Lieu, Y. Hsu, T. Yang, T. Chen, T. Ku, and T. Liang 1999. Sprinkling and forced ventilation effects on physiological and reproductive responses of dairy cows during the hot season. J. Taiwan Livest. Res. 32:137-146.
Liu, H. J., and Y. Kang. 2006. Effect of sprinkler irrigation on microclimate in the winter wheat field in the North China Plain. Agric. Water Manage. 16:819-843.

McGovern, R. R. and J. M. Bruce. 2000. A model of the thermal balance for cattle in hot conditions. J. Agric. Eng. Res. 77:9192.

Mena Guerrero, Y., A. Gomez Cabrera, and J. M. Serradilla Manrique. 1993. Alleviation of heat stress in dairy cows: Sprinkling plus aeration. Arch. Zootecn. 42:89-92.

Monteith, J. L. 1973. Principles of Environmental Physics. 1973 ed. Edward Arnold Ltd. London, UK.

Omar, E. A., A. K. Kirrella, S. A. Fawzy, and F. El-Keraby. 1996. Effect of water spray followed by forced ventilation on some physiological status and milk production of post-calving Friesian cows. Alexandria J. Agric. Res. 41:71-81.

Pinheiro, M. D., and R. G. Da Silva. 1998. Hair coat characteristics and production of Holstein cows in tropical environment. I. Hair coat traits. Boltein Ind. Anim. 55:1-6.

Singletary, I. B., R. W. Bottcher, and G. R. Baughman. 1996. Characterizing effects of temperature and humidity on misting evaporative efficiency. Trans. ASAE 39:1801-1809.

Thiagarajan, M., R. D. Michael, and R. Prabaharan. 1978. Effect of sprinkling water on cross-bred cows during summer. Kerala J. Vet. Sci. 9:215-220

Turner, L. W., J. P. Chastain, R. W. Hemken, R. S. Gates, and W. L. Crist. 1992. Reducing heat stress in dairy cows through sprinkler and fan cooling. Appl. Eng. Agric. 8:251-256.

Wang, J. W., S. Y. Lu, Y. C. Hu, and T. W. Yang. 1993. Effects of evaporative cooling on lactation and reproduction of Holstein cows in summer. J. Chin. Soc. Anim. Sci. 22:163-173. 